\title{
Estimation of the Relationship among Fractional Vegetation Cover, Land Surface Temperature and Electricity Consumption in Taipei City
}

\author{
Hsiao-Tung Chang \\ Department of Urban Affair \& Environment Planning, Chinese Culture University, Taipei 111, Taiwan, R.O.C.
}

\begin{abstract}
The cooling effects of urban green vegetation cover, which can help decrease LST (land surface temperature) in urban area. When air temperature decreases, the electricity consumption of household will also mitigate loading. Meanwhile, that lack of assessment of green vegetation coverage impact to LST and electricity consumption, so that it could not clearly quantify the environmental contribution of green coves. In Taipei city, for example, FVC (fractional vegetation cover) value and LST was collected from Aster satellite remote sensing images, and data of household electricity consumption was acquired from Taiwan Power Company. Based on these three factors, it analyzed relative model. In the urban area, fractional vegetation cover might influence with land surface temperature and electricity consumption. The result shows that when the value of fractional vegetation cover is low, the air temperature is high. While fractional vegetation cover is increase, not only the land surface temperature is decreasing but the electricity consumption is also reducing. This study hopes can be the reference materials for the future metropolis plan and to inhibit the spread of urban thermal environment.
\end{abstract}

Key words: Remote sensing, FVC, LST, aster satellite images, electricity consumption.

\section{Introduction}

In Taipei, the capital of Taiwan, summer temperature was as high as $38.6^{\circ} \mathrm{C}$, and the average urban air temperature has risen by $1.82{ }^{\circ} \mathrm{C}$ over the last century. Part of the rise in the air temperature due to global warming, on the other hand, the significant rise reason caused by UHI (urban heat islands), more importantly, depends on the development of urban areas, man-made environment and land use activities affected. In addition, UHI leads to an increase in the energy consumption [1]. As reported by the Taiwan Power Company, the air temperature increase for each $1{ }^{\circ} \mathrm{C}$ rise is equivalent to $3 \%$ of this base electricity load over the $30{ }^{\circ} \mathrm{C}$ summer time.

Many manage measures against UHI have been considered, primarily to decrease the air temperature.

Corresponding author: Hsiao-Tung Chang, Ph.D., associate professor, research fields: urban design, urban planning, remote sensing and eco-city. E-mail: changht4613@gmail.com.
During the summer months, such green vegetation cover might reduce outside air temperatures, then reducing energy consumption. About $45 \%$ of Taiwan's electricity consumption in summer was use of electricity in the air condition, to reduce the urban heat environmental discomfort. Urban thermal environment mainly affected by climatic factors, more importantly, depends on the development of urban areas, residence patterns and land use activities influenced [2].

In response to urban heat island effect, increase green area and fractional vegetation cover is considered to be the main measures to reduce air temperature, while lowering the air temperature is an important factor in saving power consumption. Green coverage can slow down the surface temperature increases. Also it has a great effect to improve the heat island phenomenon, every $10 \%$ increase green cover, and then the temperature can be reduced $0.5{ }^{\circ} \mathrm{C}$ of Taipei [3]. Many studies have investigated electric 
power consumption, most of these studies have aimed to quantify the impacts of climate changes on the energy demand in urban environment [4]. The other studies have been based on electricity consumption data with not only monthly or daily but also hourly intervals for collecting the data. The main purpose of this study is to analyze the correlation of vegetation cover, temperature and electricity consumption. In Taipei city, for example, by Aster satellite remote sensing images to analyze FVC (fractional vegetation cover) value and LST (land surface temperature), then energy information provided by each household electricity consumption data supported by Taiwan Power Company. Based on three factors, it analyzed relative model. This research includes: (1) research and analysis FVC, LST and energy consumption of the summer day of Taipei; (2) relationship analysis among fractional vegetation cover, land surface temperature and energy consumption.

\section{Study Area and Data}

Remote sensing methods proposed in this study were applied in urban areas, Taipei Taiwan. Taipei city is located in the Taipei Basin in northern Taiwan. Climate is sub-tropical climate on the distribution area, in 2012 the annual average temperature of $23.2^{\circ} \mathrm{C}$, the average relative humidity of $76.6 \%$, the average number of $1,405 \mathrm{~h}$ of sunshine, rainfall $2,405 \mathrm{~mm}$, rainy days almost 165 days a year. Taipei city is situated in the northern part of Taiwan Island to include the northeast of the Taipei Basin and the surrounding hill areas. It borders Taipei county all around (Fig. 1). The length from north to south is $27.66 \mathrm{~km}$, and width from east to west is $20.75 \mathrm{~km}$, that total areas are $271.8 \mathrm{~km}^{2}$. At the end of 2011 , the population reached 2,650,968.

Orthorectified Aster (advanced spaceborne thermal emission and reflection) radiometer imagery of the study area was obtained for the image date 15 July 2012 from the USGS (US Geological Survey). A false color composite of the study area image is shown in
Fig. 1. For this study, the $15 \mathrm{~m}$ resolution red (0.63-0.69 $\mu \mathrm{m})$ and near infrared (nir: 0.76-0.86 $\mu \mathrm{m}$ ) image bands were used for calculating FVC indices, and thermal infrared bands (10.25-11.65) were used for calculating surface temperatures.

\section{Methodology and Data Processing}

\subsection{Fractional Vegetation Cover}

FVC, which is defined as the percentage of vegetation occupying a unit area which is derived from

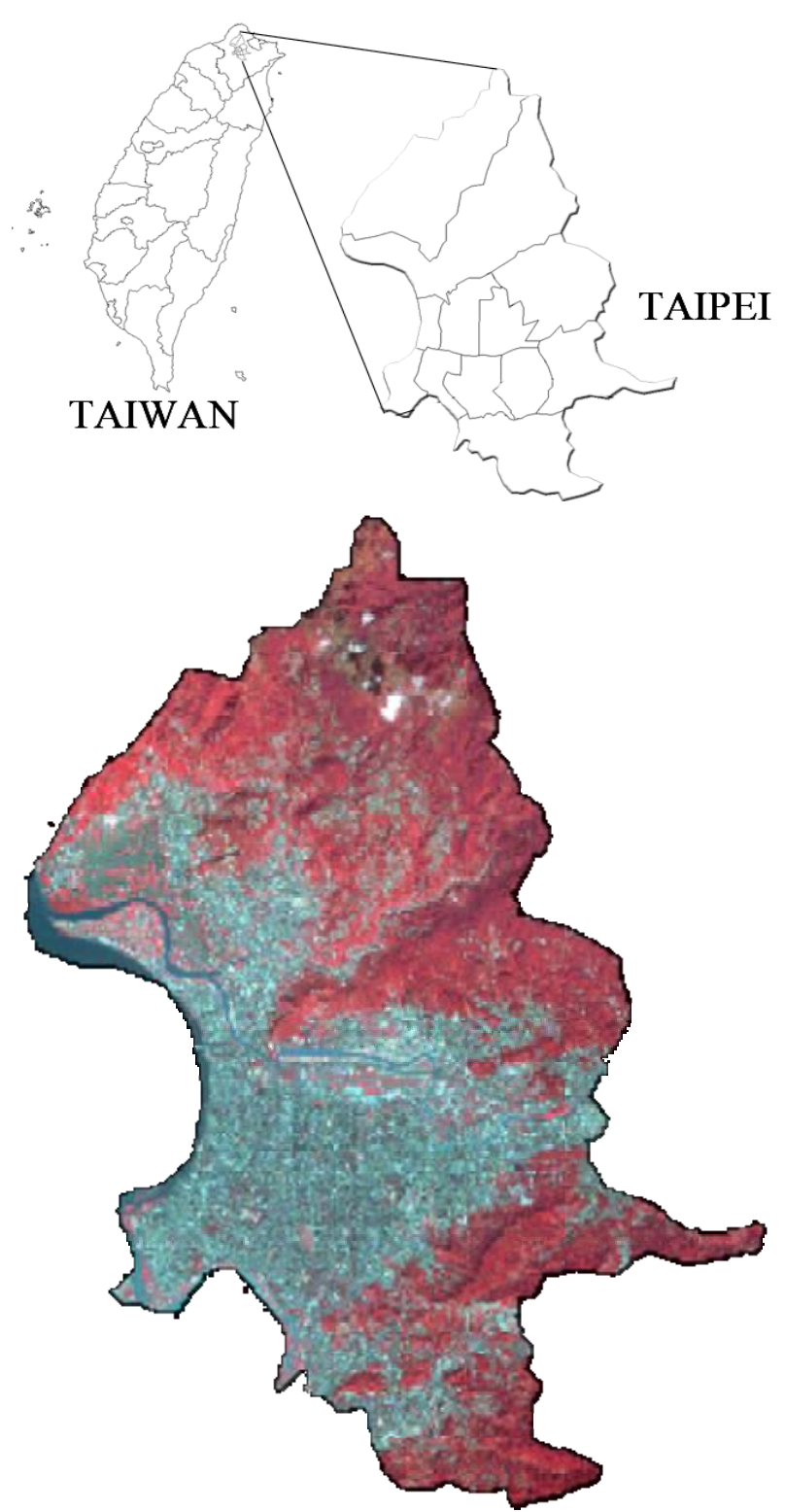

Fig. 1 The location of study area (Taipei, Taiwan) and its Aster satellite images. 
remote sensing data, in urban areas may also influence air quality and even human health [5]. There are three different kind of methods used now in FVC estimation, field measurements, spectral mixture analysis and vegetation indices. Field measurement is usually too expensive, spectral mixture analysis decomposes each pixel into a linear component [6] which methods are difficult to apply to regions with urban and suburban areas with a homogeneous land surface [7], vegetation indices established empirical relationships between the ground and vegetation indices. In this research, the study areas were for the most part of urban areas. Consequently, we also explored a transformation of NDVI (normalized difference vegetation index) into values associated with cover fraction using empirical relations with vegetation indices, as a possible basis function. NDVI given by:

$$
N D V I=\frac{B_{n i r}-B_{r e d}}{B_{n i r}+B_{r e d}}
$$

where, nir is at-surface reflectivity obtained from that located in the near infrared (nir) spectral region, and red is at red spectral region. FVC can be estimated from NDVI, for example using the form suggested by Choudhury et al. [8]:

$$
F V C=1-\left(\frac{N D V I_{\max }-N D V I}{N D V I_{\max }-N D V I_{\min }}\right)^{0.625}
$$

where, $\mathrm{NDVI}_{\min }$ and $\mathrm{NDVI}_{\max }$ nominally describe the minimum and maximum of NDVI values expected within the scene, and are determined here by the lower and upper $3 \%$ tails of the NDVI distribution, chosen to exclude outliers.

Fig. 2 shows the FVC distributions on July 15, 2012, from which we can also see that the vegetation density was scarce in the urban areas almost under $20 \%$. Mountain areas on suburban were rich vegetation cover, most of them over $50 \%$. There was average $34.5 \%$ in whole city.

\subsection{Land Surface Temperatures}

Various algorithms have been developed for converting Aster TIR (thermal infrared) measurements to LST as reported by the Aster temperature/emissivity working group [9] and Hulley et al. [10].

However, a universally accepted method is not available at this time for computing LSTs from multiple bands of TIR data such as those found in Aster data. In this study, we selected Aster band 13 and $14(10.25-11.65 \mu \mathrm{m})$ to compute LST, because the spectral width of this band is close to the peak radiation of the black-body spectrum given off by the urban surface of the study area. Two steps were taken to compute LST: (1) converting spectral radiance to at-sensor brightness temperature (i.e., black-body temperature); (2) correcting for spectral emissivity. We adopted the most straightforward approximation to replace the sensor response function with a delta

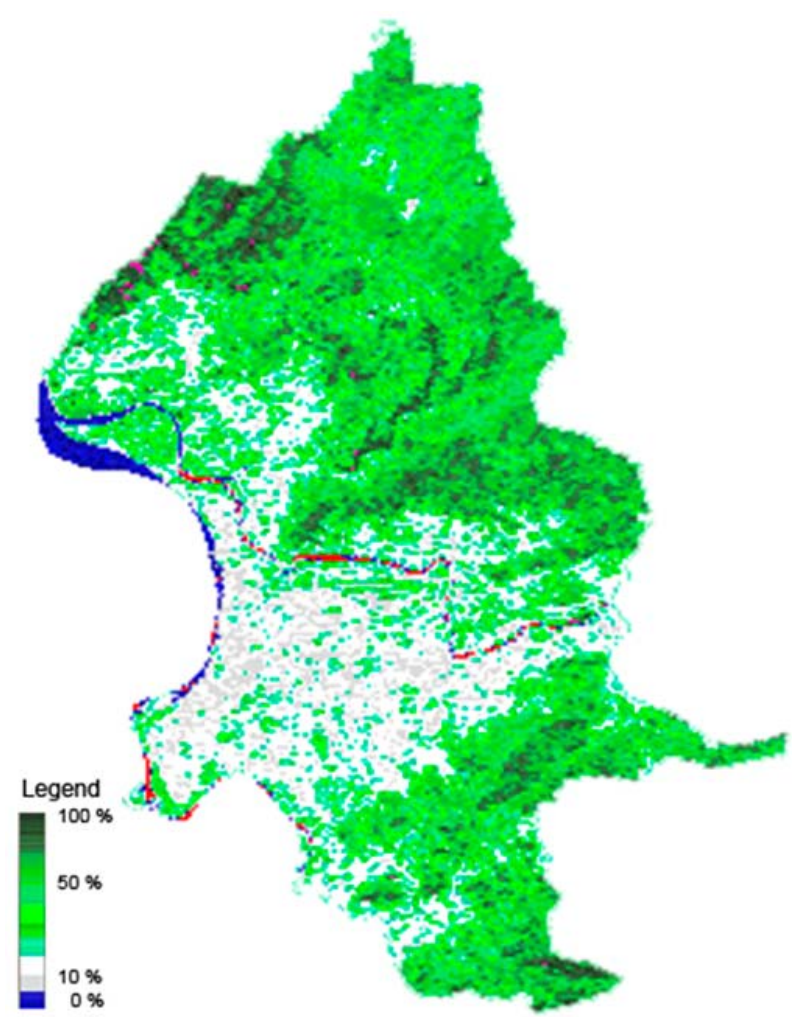

Fig. 2 FVC (fractional vegetation cover) of Taipei, by ASTER on July 15, 2012. 
function at the sensor's central wavelength to invert LST with the assumption of uniform emissivity [11, 12]. That conversion formula is:

$$
T_{c}=\frac{K_{1}}{\lambda_{c} \ln \left(\frac{K_{2}}{\lambda_{c} \pi L_{\lambda}}+1\right)}
$$

where, $T c$ is brightness temperature in Kelvin $(\mathrm{K})$ from a central wavelength, $L_{\lambda}$ is spectral radiance in $\mathrm{W} \cdot \mathrm{m}^{-3} \cdot \mathrm{sr}^{-1} \mu \mathrm{m}^{-1} ; \lambda_{c}$ is the sensor's central wavelength. For Aster images, $K_{l}$ is the second radiation constant $(0.0143879 \mathrm{~m} \cdot \mathrm{K}) ; K_{2}$ is first radiation constant $\left(3.74151 \times 10^{-16} \mathrm{~W} \cdot \mathrm{m}^{-2} \cdot \mathrm{sr}^{-1} \cdot \mu \mathrm{m}^{-1}\right)$. The temperature values obtained above are referenced to a black body. Therefore, corrections for spectral emissivity $(\varepsilon)$ became necessary according to the nature of land cover. Each of the land-cover categories was assigned an emissivity value according to the emissivity classification scheme by Jiménez-Muñoz et al. [13]. The emissivity-corrected LSTs were computed as follows:

$$
L_{T}=\frac{T_{c}}{1+\left(\frac{\lambda^{*} T_{c}}{\rho}\right) \ln \varepsilon}
$$

where, $\lambda=$ wavelength of emitted radiance (for which the peak response and the average of the limiting wavelengths $(\lambda=10.6 \mu \mathrm{m})$ was used when calculate band 13), $\rho=h \times c / \sigma\left(1.438 \times 10^{-2} \mathrm{~m} \cdot \mathrm{K}\right), \sigma=$ Boltzmann constant $\left(1.38 \times 10^{-23} \mathrm{~J} \cdot \mathrm{K}^{-1}\right), h=$ Planck's constant $\left(6.626 \times 10^{-34} \mathrm{~J} \cdot \mathrm{s}\right)$, and $c=$ velocity of light $\left(2.998 \times 10^{8} \mathrm{~m} \cdot \mathrm{s}^{-1}\right)[14]$.

From the derived emissivity values $(\varepsilon)$, the maximum values are observed over agricultural cropland that ranges from 0.964 to 0.975 (mean of 0.970 and standard deviation of 0.0018 ). Dense vegetation (mainly forest) depicted emissivity values in the range 0.955 to 0.970 (mean of 0.961 and standard deviation of 0.001 ) as the vegetation in forest area is of shrubs type (water has the highest emissivity value). The emissivity values on high dense built-up and commercial, industrial are found to be in the range of 0.92 to 0.96 (mean of 0.943 and standard deviation of 0.002). That it depends its land use tape to value emissivity values $(\varepsilon)$ in the formula, then we averaged calculate $L_{T}$ from band 13 and 14 to get the map of land surface temperatures (Fig. 3).

\subsection{Electricity Power Consumption}

The electric power consumption data were obtained from Taiwan Power Company, which data were include nine district of Taipei. The hourly data span the period from January 1 to December 31, 2012. That is to analyze the hourly electric power consumption to meteorological elements. However, these data can be analyzed in an area of full year's consumption, but also one day is able to choose the distribution analysis for power consumption of whole city.

When benchmark the building in energy use, one of the key metrics you will see is energy use intensity, or call EUI (energy use intensity). Essentially, the EUI expresses a building's energy use as a function of its size or other characteristic. As the metric of EUI, in here we took GEUI (gross energy use intensity) to analysis, it defined as a measure of district energy use per unit area. Energy demand can be gauged by degree-days, average monthly values, one hour of electricity. Formula as follows:

$$
G E U I=\frac{M W h \times 1,000(k W h)}{A} \times 1,000
$$

where, numerator is average one hour degree of total energy consumed in one month (or one day) (kWh), and denominator is total areas of the districts $\left(\mathrm{m}^{2}\right)$. That unit is $\mathrm{Wh} / \mathrm{m}^{2} / \mathrm{mo}$ for month and $\mathrm{Wh} / \mathrm{m}^{2} / \mathrm{d}$ for day. Same as this measure formula, we may analyze GEUIm $\left(\mathrm{Wh} / \mathrm{m}^{2} / \mathrm{mo}\right)$ represent month, and GEUId $\left(\mathrm{Wh} / \mathrm{m}^{2} / \mathrm{d}\right)$ represent one day.

In this study, power consumption data included nine districts, each district includes residential land use areas are $30 \%$ to $40 \%$, and commercial land use areas are $10 \%$ to $20 \%$, and the other are schools and public facilities. On July 2012, average one hour degree of total energy consumed in one month (GEUIm) scale of 60 to $625\left(\mathrm{Wh} / \mathrm{m}^{2} / \mathrm{d}\right)$. 


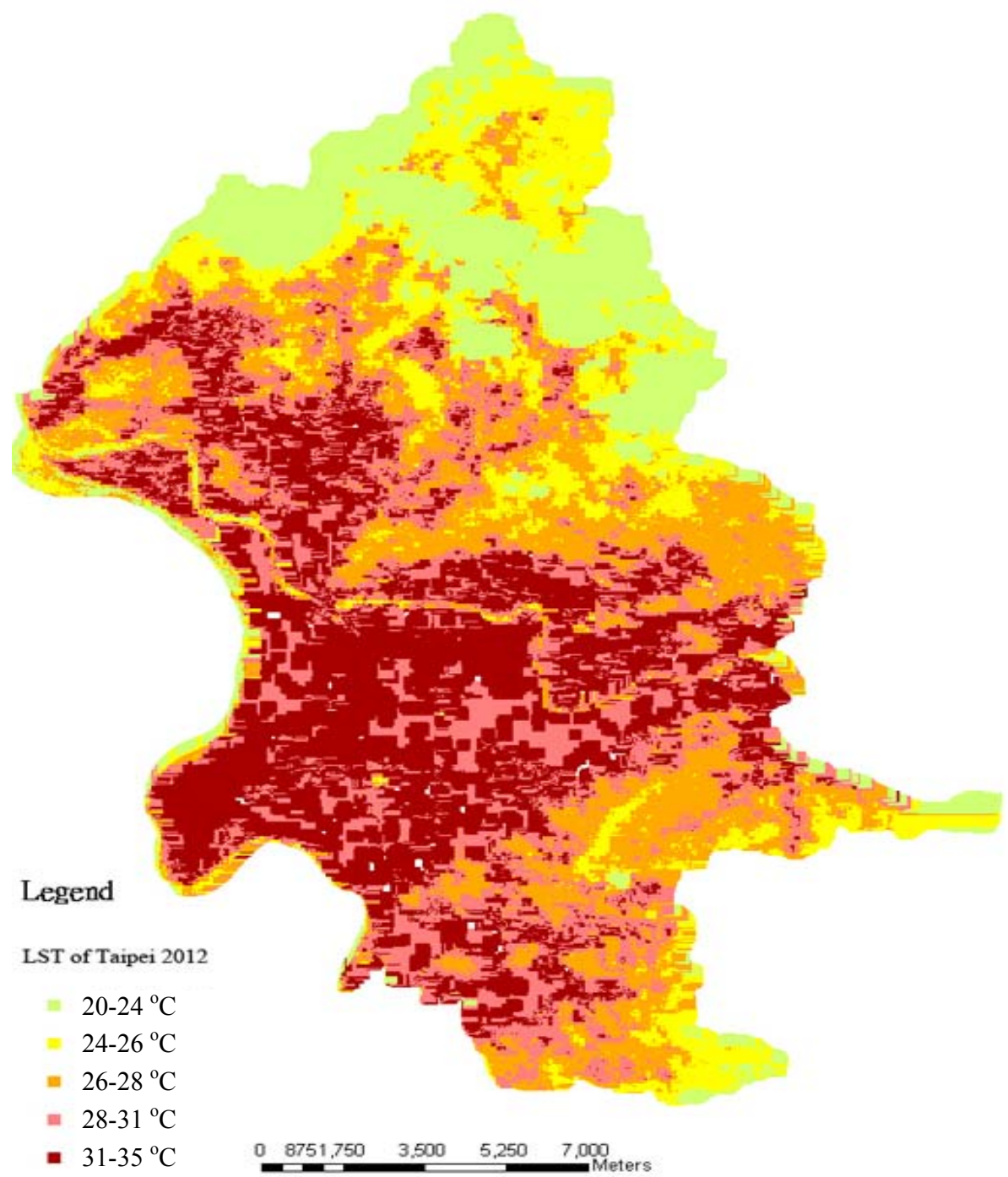

Fig. 3 LST of Taipei by Aster on July 15, 2012.

\section{Analysis and Discussion}

\subsection{Analyses of FVC Using Aster Image Data}

Multi-temporal Aster thermal and reactive data were used to study the spatial analysis of LST in relation to a vegetation index in Taipei, the metropolis urban area in the north of Taiwan. Minimum noise fraction was performed on the Aster data to reduce the data redundancy and correlation between spectral bands. FVC was applied to band 1 to 3 of the Aster images. For image classification, unit of urban blocks was initially performed on Aster data for an idea of the same relatively unit of FVC, LST and GEUI. Digital urban planning maps of GIS (geographic information system) was used to select as a comparatively platform. Based on the FVC maps sets by the Aster data, point shape file data format was selected in the intermediary data from remote sensing to GIS vectors imagery.

Fig. 4 shows the spatial distribution of FVC from the Aster image on July 15, 2012. The FVC values estimated are in the range of $0.34 \%$ to $100 \%$, having a mean value of $24.34 \%$ with standard deviation of 0.15804 , the lower quartile is $14.93 \%$ even the higher quartile is only $27.05 \%$. It is seen that lower FVC value (bright areas) corresponds to high dense built-up area on the central business district of Taipei. Higher FVC values (dark area) are observed in the north-east 


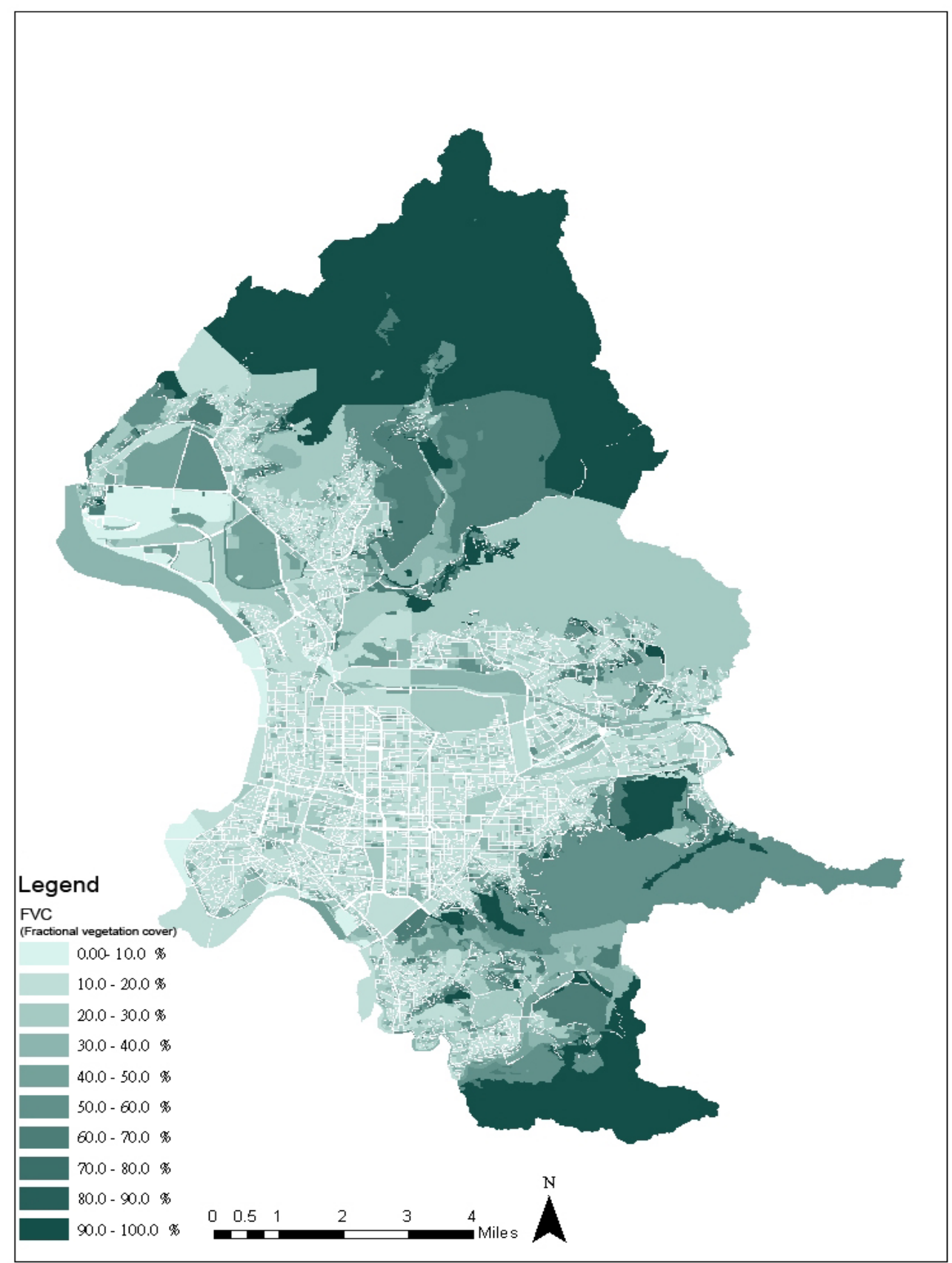

Fig. 4 FVC of Taipei (GIS map).

and south-east part of city. Medium FVC values (grey green areas to bright areas) are observed over agricultural croplands and suburban low density land use. Analysis between the NDVI and the FVC image shows a positive Pearson's correlation coefficient of 0.6137 and correlation is significant at the level less than 0.001 (1-tailed). It is also observed that the relationship between these two vegetation indicators is a linear for different land use and land cover categories. These results are further analyzed with surface temperature.

\subsection{Analysis of LST of Aster Image Data}

LST was applied to band 13 to 14 of the Aster images. For image classification, unit of urban blocks was initially performed on Aster data for an idea of 
the same relatively unit of FVC, LST and GEUI. Therefore, digital urban planning maps of GIS was used to select as a comparatively platform. The LST maps data were transformed to shape-file data format, and then it was averaged in same block data and setup to GIS vectors imagery.

The hot spots displayed as dark color could be easily identified in Fig. 5, which shows the spatial distribution of surface temperature of Aster image on July 15, 2012. For comparison purpose, the field measurements were taken in July 2012 keeping the time and same period of season. In order to compare the estimated surface temperature values from satellite data with the field measurements, a field fixed stations campaign from July 15 was carried out and measurements were taken over different land use and zoning features. The comparison between the satellite derived surface temperature values with that of field measured and is inferred that the retrieved values are in good agreement with an error of around $3.5^{\circ} \mathrm{C}$. Finally, the adjusted LST ranged from $21.64{ }^{\circ} \mathrm{C}$ to $39.26{ }^{\circ} \mathrm{C}$ (mean of $29.56{ }^{\circ} \mathrm{C}$ and standard deviation of $3.589^{\circ} \mathrm{C}$ ). It is observed from the image that west and south-west part exhibits high temperature mainly due to higher density building area.

Some of the high temperature zones are also seen in the central part of the city mainly due to commercial and high density residential land use. Commercial and residential land use surface temperature ranges from $23.6{ }^{\circ} \mathrm{C}$ to $39.2{ }^{\circ} \mathrm{C}$ (mean value $33.74{ }^{\circ} \mathrm{C}$ ). Apparently, each land surface temperature in urban landscapes exhibited land use type and related to their surrounding site environment. It was clear that average LST increased to $28.25{ }^{\circ} \mathrm{C}$ and exhibited the relative highest temperature at $34.46{ }^{\circ} \mathrm{C}$. On the contrary, when deduct the farmland and mountain districts the average temperature of urban land use area was $32.37{ }^{\circ} \mathrm{C}$ of city. The relative highest temperature show in commercial land use areas. This implied that urban development brought up an average of $3-4{ }^{\circ} \mathrm{C}$ by replacing natural environment (grassland, forest and bare land) with non-evaporating, non-transpiring surfaces, such as asphalt, metal and concrete buildings.

\subsection{Analysis of GEUI (Gross Energy Use Intensity)}

Gross energy use intensity was defined as district energy use per unit area. The data through year 2012 was obtained from Taiwan Power Company. The daily energy intensity in Taipei ranged from 60 to over $600\left(\mathrm{Wh} / \mathrm{m}^{2} / \mathrm{d}\right)$, which was in strong relation with green coverage and surface temperature. Fig. 6 shows the spatial distribution of GEUId from the power supply by Taiwan Power Company on July 15, 2012.

The GEUId values estimated was mean of 269.06 $\left(\mathrm{Wh} / \mathrm{m}^{2} / \mathrm{d}\right)$ with variance of 40.08 , the lower quartile is $213.8\left(\mathrm{Wh} / \mathrm{m}^{2} / \mathrm{d}\right)$ the higher quartile is 300 $\left(\mathrm{Wh} / \mathrm{m}^{2} / \mathrm{d}\right)$. It is seen that lower GEUId value (bright areas) corresponds to high dense green cover area on the north-east and south-east part of Taipei. Higher GEUId values (dark area) are observed in the center of city. Medium GEUId values (bright brown areas) are on the south-east and south-west part of city.

\subsection{Relationship among FVC, LST and GEUId}

According to city-block-scale, it took whole Taipei city to analyze relationship between FVC, LST and GEUId. There were 13,956 data of blocks to calculate. Fig. 7 shows the correlation (FVC with LST and GEUId) for Taipei city areas. It is inferred that FVC values tend to be negative correlated with LST and GEUId. The regression formula between FVC with LST is LST $\left({ }^{\circ} \mathrm{C}\right)=-6.1282 \mathrm{FVC}+32.352, R^{2}=$ 0.1732 . As the result, there was linear relationship between fractional vegetation cover and land surface temperature. In Taipei, if green cover increases, the surface temperature declines. On the other hand, the regression formula between FVC with GEUId is GEUId $\left(\mathrm{Wh} / \mathrm{m}^{2} / \mathrm{d}\right)=-115.03 \mathrm{FVC}+297.06, R^{2}=$ 0.0284. There was linear relationship between fractional vegetation cover and gross energy use 


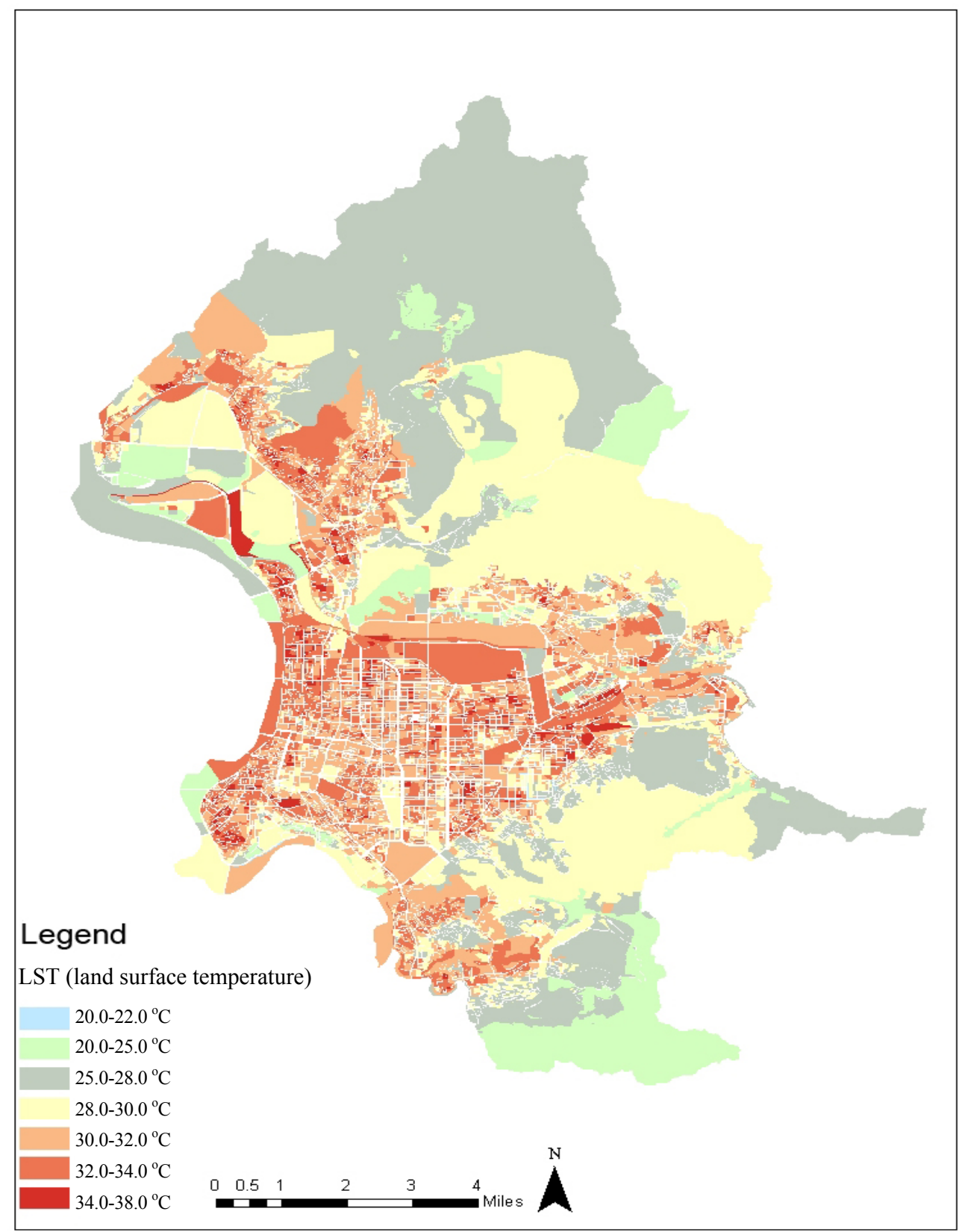

Fig. 5 LST of Taipei city (GIS map).

intensity. There was a trend that if FVC increases, the electricity consumption tends to decrease. And, as we can see, the higher the land surface temperature was, the more consumption the energy used.

\subsection{Spatial Relationships between FVC and LST}

Based on the individual street blocks of land use zoning units, a total of 13,855 documents were been overlaid FVC and LST to do analysis. To investigate the relationship of FVC-LST slope, a land cover classification was used zoning map of 28 classes land use types used on GISs. And then, a total of 28 kinds of the land use sub zoning were categorized (Table 1).

Pearson's correlation analysis was conducted to explore the relationships between LST, thermal features (i.e., man-make environment), and FVC, green cover descriptors (i.e., vegetation abundance, grasslands and soil fractions) by land-cover classes. 


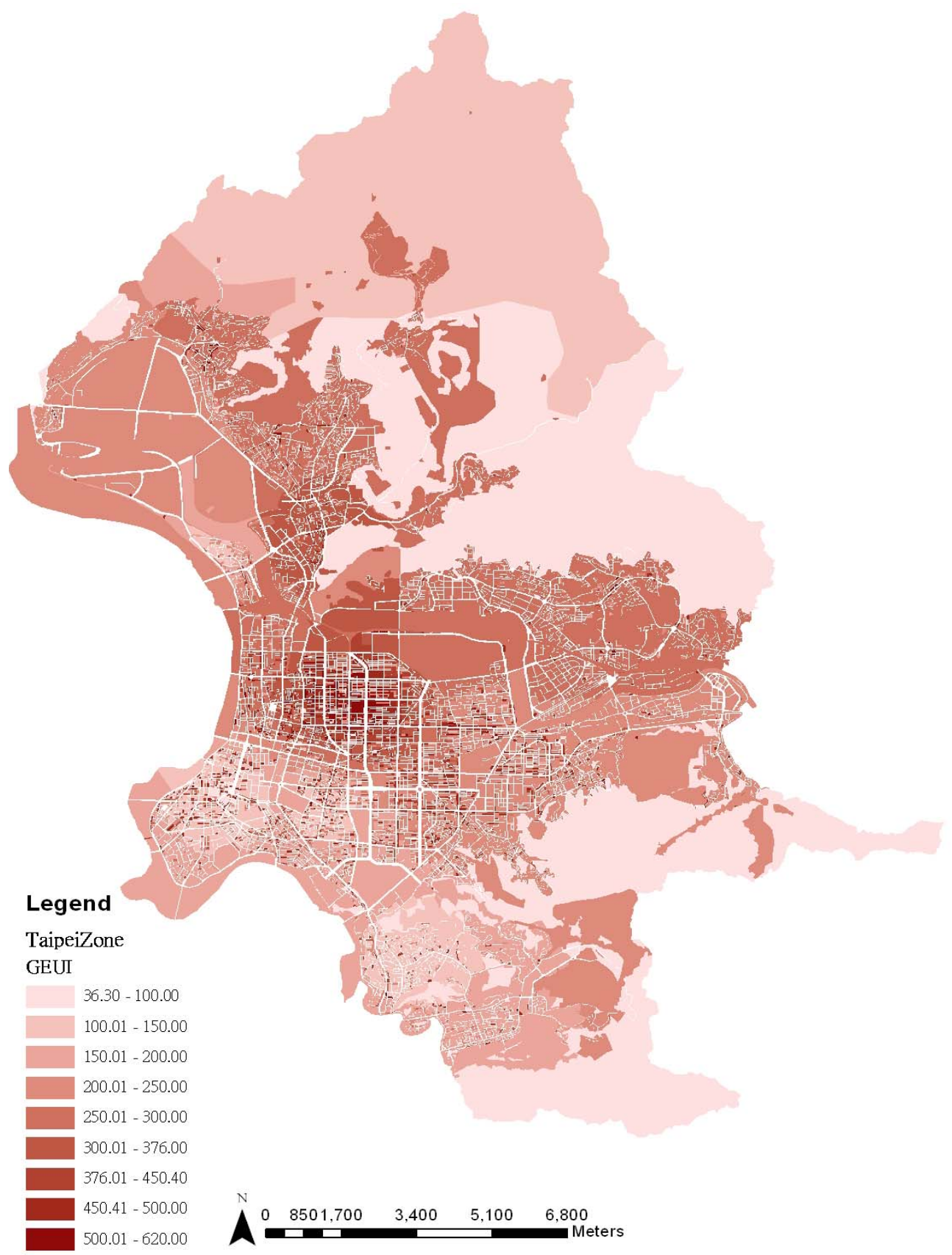

Fig. 6 Electric power consumption GEUId of Taipei.

Also, the image was mapped by urban planning, based on zoning map to class 28 land-cover types. Land use types were zoned: (1) high-density land use, such as residential area, commercial area, administrative area, industrial area, special use etc.; (2) public facilities: school, historic preservation, plaza, gas station, power substation, railroad, parking, airport, market, waster/sewage treatment etc.; (3) green-dominated lands: park, recreation, national park, entertainment, scenic area, conservation district, green space, agriculture; (4) transportation area, freeway, and so on.

Multiple regression analysis was further conducted to assess the relative importance of each FVC variable for explaining LST patterns. The coefficient of determination $\left(R^{2}\right)$ was used to evaluate regression 


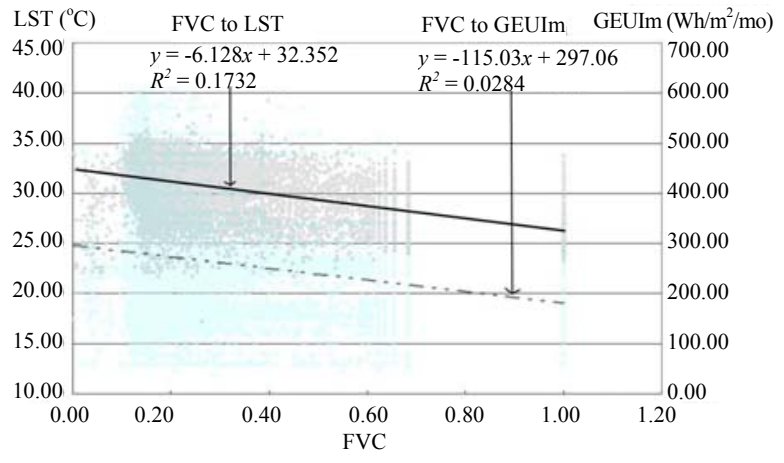

Fig. 7 Regression relationship among FVC, LST and GEUI.

model performance. Beta values were computed to measure the changes of different variables on a standard scale, and to indicate how much change in the dependent variable was produced by a standardized change in one of the explanatory variables when the others were controlled. The value of each sample was retrieved based on each derived variable.

It can be seen from the relationship between FVC and LST, which a parabolic regression curve showing the straight down to the right as a negative correlation relationship (Fig. 8). LST $\left({ }^{\circ} \mathrm{C}\right)=-0.0007(\text { FVC })^{2}+$ $0.0316(\mathrm{FVC})+33.556 R^{2}=0.6565$. The $\mathrm{F}$ test of formula is $24.504, p$-value of independent variable, $\mathrm{FVC}$, is less than 0.00003 .

\subsection{Spatial Relationships between LST and GEUI}

When we analyzed the hourly data of whole year, which electric power consumption data were from Taiwan Power Company and comparatively temperature data were from fixed weather station as the similar location. Take the example of Shilin residential district, the monthly electricity consumption (GEUIm) is shown in Fig. 9. The GEUIm curve is tendency towards the temperature curve and its consumption has increased 1.7 times from lowest to highest during one year. Meanwhile, electricity consumption is increase as temperature is decrease in the winter day. It shows a strong seasonal cycle, demonstrating a temperature-dependent characteristic.

Fig. 10 illustrates scatter diagrams and regression curve which show the inter-relationship between the daily average electricity consumption and the daily mean temperature. In general, electricity consumption increases when the temperature rises. The temperature function of electricity was best fit by a power 2 polynomial curve fitting tendency revealed that daily electricity consumptions within one year are clearly

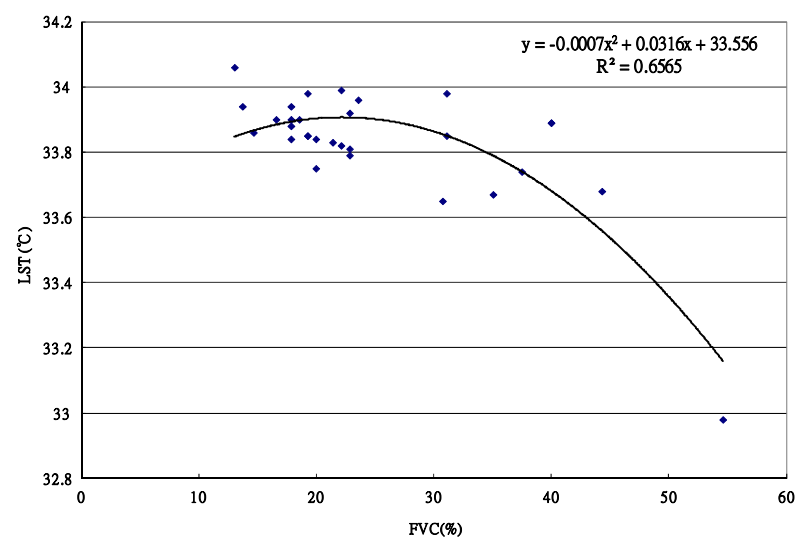

Fig. 8 Correlation relation between FVC and LST in July 15, 2012 Taipei.

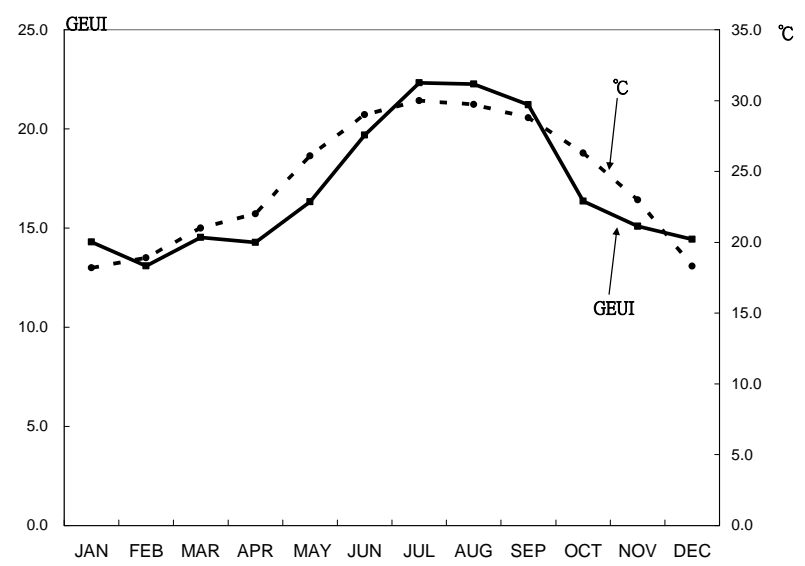

Fig. 9 The monthly electricity consumption (GEUIm) and temperature in Shilin district, Taipei (2012).

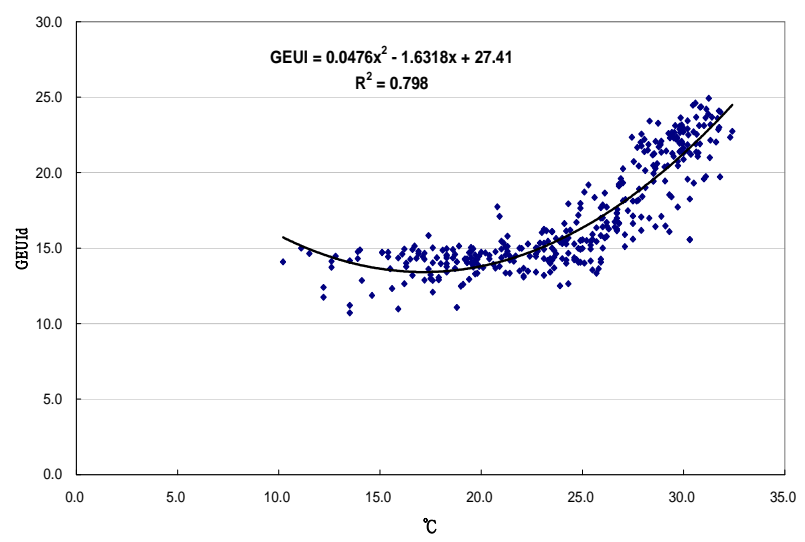

Fig. 10 The daily electricity consumption (GEUId) and temperature in Shilin district, Taipei (July 2012). 
Table 1 The FVC and LST of urban planning land use.

\begin{tabular}{lll}
\hline Land use & LST $\left({ }^{\circ} \mathrm{C}\right)$ & FVC $(\%)$ \\
\hline Residential area & 33.65 & 30.741 \\
Commercial area & 33.86 & 14.659 \\
Oil facilities & 33.84 & 19.961 \\
Administrative area & 33.82 & 22.109 \\
School & 33.83 & 21.389 \\
Cemetery & 33.74 & 37.479 \\
Gas storage & 33.98 & 19.253 \\
Waster/sewage treatment & 33.85 & 31.085 \\
Market & 33.85 & 19.253 \\
Historic Preservation & 33.90 & 18.548 \\
Gas station & 33.90 & 17.847 \\
Power substation & 33.94 & 17.847 \\
Railroad & 33.94 & 13.715 \\
Airport & 33.99 & 22.109 \\
Parking & 33.75 & 19.961 \\
Freeway & 33.89 & 39.980 \\
Transportation area & 33.85 & 19.253 \\
Plaza & 33.88 & 17.847 \\
Recreation & 33.89 & 39.980 \\
National park & 32.98 & 54.587 \\
Entertainment & 33.84 & 17.847 \\
Scenic area & 33.98 & 31.085 \\
Conservation district & 33.68 & 44.294 \\
Green space & 33.79 & 22.832 \\
Industrial area & 33.9 & 16.577 \\
Agriculture & 33.67 & 22.832 \\
Special use & 34.46 & 22.832 \\
Other & 33.96 & 23.560 \\
\hline temperature dependent. & 16985 \\
\hline
\end{tabular}

temperature dependent. The regression functions were satisfied at 0.05 significance level and $R^{2}$ correlation coefficients exceeded 0.798 . So, that may say, the higher the land surface temperature was, the more consumption the energy used.

\section{Conclusions}

In this paper, quantitative analyses have been used to study the relationship among FVC, LST and GEUI. It demonstrates how fraction images derived from an FVC approach can be used to examine the relationships with LST under the urban environment. LST was found to correlate positively with high-density land use, but negatively with greenery areas. High-density land use such as commercial, residential district posed a stronger impact on LST than cold objects such as park, school, or cover with vegetation areas. From the relationship analysis that characterized green cover could reduce outside temperature.

Using the regression analysis, we could obtain a high-precision estimate of the electric power consumption according to air temperature. The temperature function of electricity was best fit by a polynomial curve-fitting tendency revealed that daily electricity consumptions within one year are clearly temperature dependent. Electricity consumptions of household were changed with the land surface temperature, which was proven by the higher UHI intensity on July in both city scale and district levels in this study. FVC would be another important impact factor to electricity consumption, and the electricity consumption would be lower when the study area is greenery.

The results showed that fractional vegetation cover closely related land surface temperature and energy consumption. On the other hand, increased green cover can decrease urban air temperature. And as thermal temperature decreased, the power consumption of household will decline. Finally, increased green covers improve urban thermal environment and construct a better eco-city.

\section{Acknowledgments}

This work is particularly supported by academic research projects (No. NSC 101-2221-E-034-022 and NSC 102-2221-E-034- 015) of the National Science Council, Taiwan, R.O.C. those are gratefully acknowledged. Many thanks also go to all the reviewers for their constructive comments and suggestions.

\section{References}

[1] B. Bueno, L. Norford, G. Pigeon, R. Britter, A resistance-capacitance network model for the analysis of the interactions between the energy performance of buildings and the urban climate, Building and Environment 54 (2012) 116-125. 
[2] J. Martin, S.A. Kurc, G. Zaimes, M. Crimmins, A. Hutmacher, D. Green, Elevated air temperatures in riparian ecosystems along ephemeral streams: The role of housing density, Journal of Arid Environments 84 (2012) 9-18.

[3] H.T. Chang, Urban thermal environment change due to land development in Taipei City, Advanced Science Letters 19 (9) (2013) 2622-2626.

[4] T. Ihara, Y. Genchi, T. Sato, K. Yamaguchi, Y. Endo., City-block-scale sensitivity of electricity consumption to air temperature and air humidity in business districts of Tokyo, Japan, Energy 33 (2008) 1634-1645

[5] P. Bowyer, F.M. Danson, Sensitivity of spectral reflectance to variation in live fuel moisture content at leaf and canopy level, Remote Sensing of Environment 92 (2004) 297-308.

[6] J.P. Guerschman, M.J. Hill, L.J. Renzullo, D.J. Barrett, A.S. Marks, E.J. Botha, Estimating fractional cover of photosynthetic vegetation, non-photosynthetic vegetation and bare soil in the Australian tropical savanna region up scaling the EO-1 Hyperion and MODIS sensors, Remote Sensing of Environment 113 (5) (2009) 928-945.

[7] Y. Chen, P. Shi, X. Li, J. Chen, J. Li, A combined approach for estimating vegetation cover in urban/suburban environments from remotely sensed data, Computers \& Geosciences 32 (2006) 1299-1309.

[8] B.J. Choudhury, N.U. Ahmed, S.B. Idso, R.J. Reginato, C.S.T. Daughtry, Relations between evaporation coefficients and vegetation indices studied by model simulations, Remote Sensing of Environment 50 (1994)
$1-17$.

[9] ASTER Temperature/Emissivity Working Group, Temperature/Emissivity Separation Algorithm Theoretical Basis Document, Jet Propulsion Laboratory, California Institute of Technology, Pasadena, http://eospsogsfc.nasa.gov/eos_homepage/for_scientists/a tbd/docs/ASTER/atbd-ast-03.Pdf (accessed Aug. 20, 2005).

[10] G.C. Hulley, S.J. Hook, A.M. Baldridge, Investigating the effects of soil moisture on thermal infrared land surface temperature and emissivity using satellite retrievals and laboratory measurements, Remote Sensing of Environment 114 (2010) 1480-1493.

[11] P. Dash, F.M. Gottsche, F.S. Olesen, H. Fischer, Land surface temperature and emissivity estimation from passive sensor data: Theory and practice-Current trends, International Journal of Remote Sensing 23 (2002) 2563-2594.

[12] F. Li, T.J. Jackson, W.P. Kustas, T. Schmugge, A.N. French, M.H. Cosh, Deriving land surface temperature from Landsat 5 and 7 during SMEX02/SMACEX, Remote Sensing of Environment 92 (2004) 521-534.

[13] J.C. Jiménez-Muñoz, A.J. Sobrino, A. Gillespie, D. Sabol, W.T. Gustafson, Improved land surface emissivities over agricultural areas using ASTER NDVI, Remote Sensing of Environment 103 (2006) 474-487.

[14] X. Cao, A. Onishi, J. Chen, H. Imura, Quantifying the cool island intensity of urban parks using ASTER and IKONOS data, Landscape and Urban Planning 96 (2010) 224-231. 